Wayne State University

\title{
DigitalCommons@WayneState
}

Library Scholarly Publications

Wayne State University Libraries

$1-1-2006$

\section{Collaborating with Community Partners to Provide Health Information in Arabic}

Deborah H. Charbonneau

Wayne State University, dcharbon@wayne.edu

Annette M. Healy

WayneState University, amhealy@wayne.edu

\section{Recommended Citation}

Charbonneau, Deborah H. and Healy, Annette M., "Collaborating with Community Partners to Provide Health Information in Arabic" (2006). Library Scholarly Publications. Paper 31.

http://digitalcommons.wayne.edu/libsp/31

This Article is brought to you for free and open access by the Wayne State University Libraries at DigitalCommons@WayneState. It has been accepted for inclusion in Library Scholarly Publications by an authorized administrator of DigitalCommons@WayneState. 


\title{
Collaborating with Community Partners to Provide Health Information in Arabic
}

\author{
Deborah H. Charbonneau \\ Annette M. Healy
}

\begin{abstract}
Locating quality consumer health information in languages other than English can be challenging in a complex electronic information environment. Locating consumer health information in Arabic is especially difficult. At present, electronic health information in Arabic is limited in scope, not easily accessible, and poorly organized. An academic medical library collaborated with community partners to identify and bring together multiple sources of Arabic language health information in one convenient location. As a result, over 80 electronic Arabic language health materials are organized and available via the World Wide Web for health information seekers to access, view, and print. This paper will outline the need for reliable electronic health information in Arabic, describe the important role of community partners in helping libraries identify appropriate health materials for target communities, and discuss future directions for the online collection of Arabic language health materials. [Article copies available for a fee from The Haworth Document Delivery Service: 1-800-HAWORTH. E-mail address: <docdelivery@haworthpress.com> Website: <http://www. HaworthPress.com> 102006 by The Haworth Press, Inc. All rights reserved.]
\end{abstract}

KEYWORDS. Consumer health information, ethnic populations. underserved populations, Arabic health information, Internet. multilingual materials

Deborah H. Charbonneau, ML. S (dcharbon@wayne.edu) is Principal Investigator, Urban Health Partners and Coordinator for Information Access and Delivery; and Annette M. Healy, MLIS, PhD (amhealy@wayne.edu) is Information Services Librarian; both at Vera P. Shiffman Medical Library, 4325 Brush Street, Wayne State University, Detroit, MI 48201.

Journal of Consumer Health on the Internet, Vol. 10(2) 2006

Available online at http://www.haworthpress.com/web/JCHI

(C) 2006 by The Haworth Press, Inc. All rights reserved. doi:10.1300/J381v10n02 01 


\section{INTRODUCTION}

Addressing the health information needs of diverse, multi-ethnic, and multi-lingual communities can be challenging for libraries. The Vera P. Shiffman Medical Library at Wayne State University in Detroit, Michigan is the only academic medical library in Detroit open to the public and provides library services to many communities in southeastern Michigan. According to 2000 Census data, the diverse geographic area served by the library includes the nation's highest concentration of Arab Americans.' An understanding of this population in Michigan, and in the United States, will be increasingly important for libraries responsible for providing critical library services and developing resources to meet the needs of Arab American health consumers.

Library staff became aware of difficulties in locating culturally relevant health information for Arab Americans, including health information in Arabic, while attending community health fairs. At these fairs, librarians were asked for assistance in locating health information about Ramadan and fasting, as well as other nutrition information in Arabic. Existing online materials in Arabic were very limited and difficult to locate. These concerns generated the idea for establishing an easy-to-use online collection of culturally appropriate health information for this underserved population. To accomplish this, library staff sought to locate, organize, and disseminate electronic materials in Arabic that addressed relevant health issues for local Arab American communities via the World Wide Web.

Library staff established partnerships with a large county health department and a community-based organization that possessed cultural ties with the local Arab American community. It was clear from the beginning that the project's success would be dependent on community endorsement, involvement, and participation. Full collaboration with a community-based organization primarily serving the local Arab American community was essential in gaining community trust, gaining a deeper understanding of the information needs and health concerns of this community, and identifying collaborative ways of addressing the health information needs of Arab American consumers. The Urban Health Partners program, funded in 2003 by the National Network of Libraries of Medicine (NN/LM) Greater Midwest Region, was established in part to gain a better understanding of the health information needs of local Arab American communities and to develop culturally responsive library services and resources for this underserved population. 


\section{DEFINITION OF NEED}

The greater Detroit area is known for its diversity. The American Arab Chamber of Commerce estimates the Arab American population in Michigan at 490,000. ${ }^{1}$ In addition, Arab Americans are the third largest and fastest growing minority group in the state of Michigan with a great majority of this population clustered in Wayne County in southeastern Michigan (the location of the academic medical library). ${ }^{2}$ The largest number of new Arab immigrants to Michigan came from Iraq, followed by Lebanon, Jordan, Syria, and Egypt. ${ }^{1}$ Facilitating access to reliable online health information for this underserved community is an emerging priority for libraries and requires a proactive approach for exploring and participating with community partners in the Arab American community,

Locating consumer health information that is culturally sensitive, easily accessible, and written at the appropriate reading level for those with limited English proficiency can present a set of unique challenges. The population who identified as being of Arab-speaking ancestry in the U.S. Census grew by more than $65 \%$ between 1990 and $2000 .^{3} \mathrm{~A}$ local community-based organization serving the Arab American community in Dearborn, Michigan found that less than a quarter of its clientele had completed high school, 62\% spoke mainly Arabic at home, and $32 \%$ were literate only in Arabic. ${ }^{4}$ This organization responded to a need for health information in Arabic by producing bilingual health brochures in Arabic and English. Unfortunately, this critical health information that can facilitate more effective communication between providers and patients only existed in print format and was not widely available to health information seekers. A review of MedlinePlus $<$ http://www.medlineplus.gov> and other Internet sources confirmed that few Arabic language health materials from local or national sources appropriate for Arab American communities could be easily located.

\section{PARTNERSHIPS TO PROMOTE ONLINE ACCESS}

Libraries are partners with their respective communities when addressing information needs and services of diverse health information seekers. Identifying community partners who primarily interact and provide services to Arab Americans was the initial challenge. A key strategy in this initiative was not only to reach underserved Arab American health consumers but to also establish relationships with organiza- 
tions that served this population. Networking with key community leaders and stakeholders at various community events and health fairs as well as using public telephone directories, scanning local Arab/English newspapers, and checking local Web sites provided an overview of community resources. Analyzing and understanding the assets of potential community partners and service providers also assisted in identifying community partners with the resources to support and sustain a shared community initiative. Project staff conducted face-to-face interviews with leaders of a large county health department and a community-based organization serving the Arab American community, and developed culturally sensitive and feasible solutions to address important health issues. In collaboration, the library and its community partners worked jointly to develop and promote access to culturally sensitive electronic health information.

Meeting the health information needs of diverse consumers includes facilitating access to health information that is presented in culturally appropriate and meaningful ways, including health information that has been created and reviewed by members of target communities. Workman, Lombardo, and Le Ber noted that translations were of poor quality when online translation tools were used to translate consumer health information. Urban Health Partners staff discovered that when translating the word "cancer" using a free online Arabic-English dictionary, the resulting word represented the astrological sign "Cancer" rather than a health-related term. This finding further supports the notion that translation of health information by native speakers familiar with medical terminology and a careful review for cultural sensitivity and medical accuracy is essential.

The importance of understanding a target population includes learning about and developing sensitivity to its values, practices, and beliefs. To accomplish this, Urban Health Partners staff performed extensive research, conducted in-depth interviews with key community leaders and stakeholders, and attended community health fairs. Staff attended and participated in statewide health fairs and conferences, including "Health Issues in the Arab American Community Conference" (2003), "Symposium for Refugees and Victims of Torture" (2004), "Project Saha Transcultural Health Fair" (2004), and American Arab Nurses Association's "Building Cultural Bridges in Health Care Conference" (2005). These outreach activities provided staff with an increased knowledge of common diseases and health issues in the Arab American community. For example, staff learned that cardiovascular risk factors are greater for the Arab population than the general population of Mich- 
igan. ${ }^{4}$ In addition, people in the Arab American community are less likely to receive appropriate testing and screening for high cholesterol, breast cancer, and uterine cancer compared with the general population of Michigan. ${ }^{4}$ Furthermore, the community events and symposiums highlighted various mental health issues that refugees and new immigrants face. These experiences illuminated health priorities in the Arab American community and aided project staff in the development of the online collection of Arabic materials, which includes materials addressing cardiovascular health, cancer screening and testing, and mental health.

Urban Health Partners staff partnered with local health professionals to overcome some of the challenges often encountered when trying to identify appropriate health materials for multi-ethnic and multi-cultural health information seekers. Community organizations providing health-related services to Arab American communities in Michigan were invited to prepare and contribute culturally appropriate materials for online access. The library's relationship with a community partner that serves the Arab American community in Dearborn, Michigan, a city where roughly one-third of the population reports some Arab heritage, ${ }^{1}$ was a valuable asset and provided guidance for many activities including planning and publicity. As a result of this library-community collaboration, health information seekers can now access reliable electronic health information in Arabic developed by members of the target community with Arabic-speaking health information seekers in mind. The strategy of encouraging the participation of organizations serving Arab American communities to make information available electronically proved to be essential for identifying relevant materials for Arab American communities. In contrast, translating original documents available in English only and "pushing" the information onto the local community would not ensure that the health information was culturally appropriate and meaningful to Arabic-speaking health information seekers.

\section{HEALTH INFORMATION IN ARABIC}

The Urban Health Partners program led the development of an online collection of over 80 Arabic language health materials on the World Wide Web <http://www.lib.wayne.edu/shiffman/urbanhealth>. Electronic materials were collected and organized using three different methods, affording health information seekers multiple options for lo- 
cating health information in Arabic. Health information seekers can browse an alphabetical list of materials (see Figure 1). Titles include "Ramadan and Fasting," "Colorectal Cancer Screening for People with Medicare," and "Fitness for Seniors." Health information seekers may also consult the materials organized by health topic; topics include asthma, cancer, cardiovascular health, domestic violence, health insurance, immunizations, and mental health (see Figure 2). The Arabic language materials are also arranged by the name of the author or organization that produced the content (see Figure 3). To date, health information in Arabic from 15 different local, national, and international organizations is easily accessible from one convenient location on the World Wide Web.

The Arabic language materials produced by project partners range from single page fact sheets on lead poisoning or West Nile Virus developed by the Wayne County, Michigan Department of Public Health to more comprehensive booklets and brochures such as "Asthma Aware-

FIGURE 1. Alphabetical List of Arabic Language Health Materials

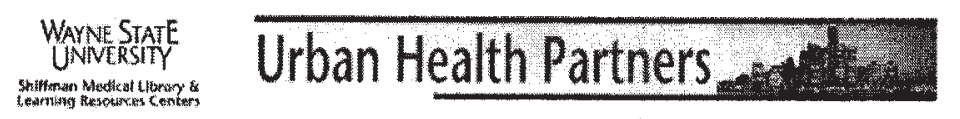

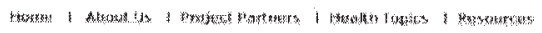

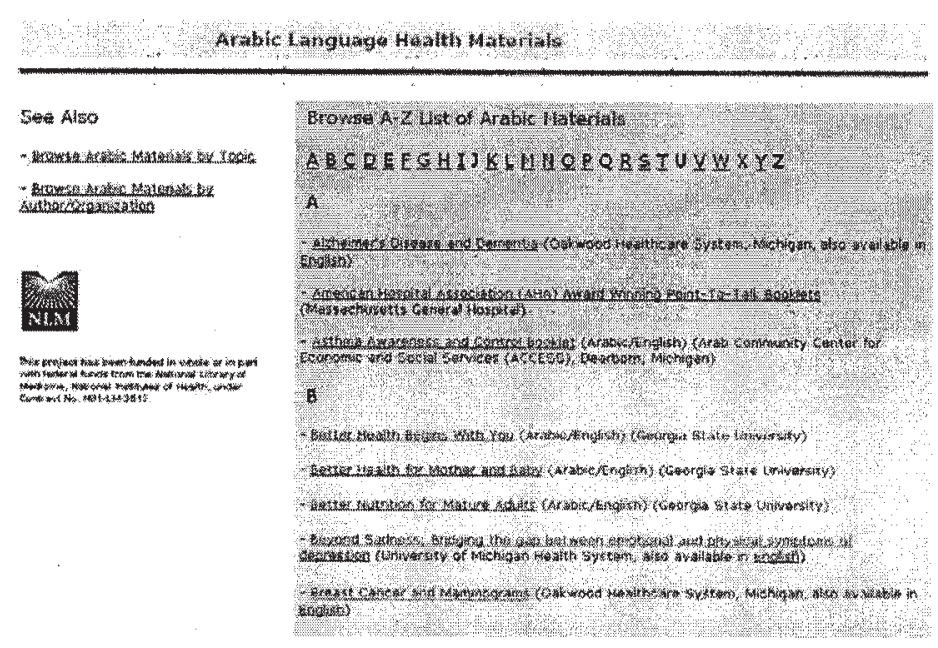


FIGURE 2. Arabic Language Materials Organized by Health Topic

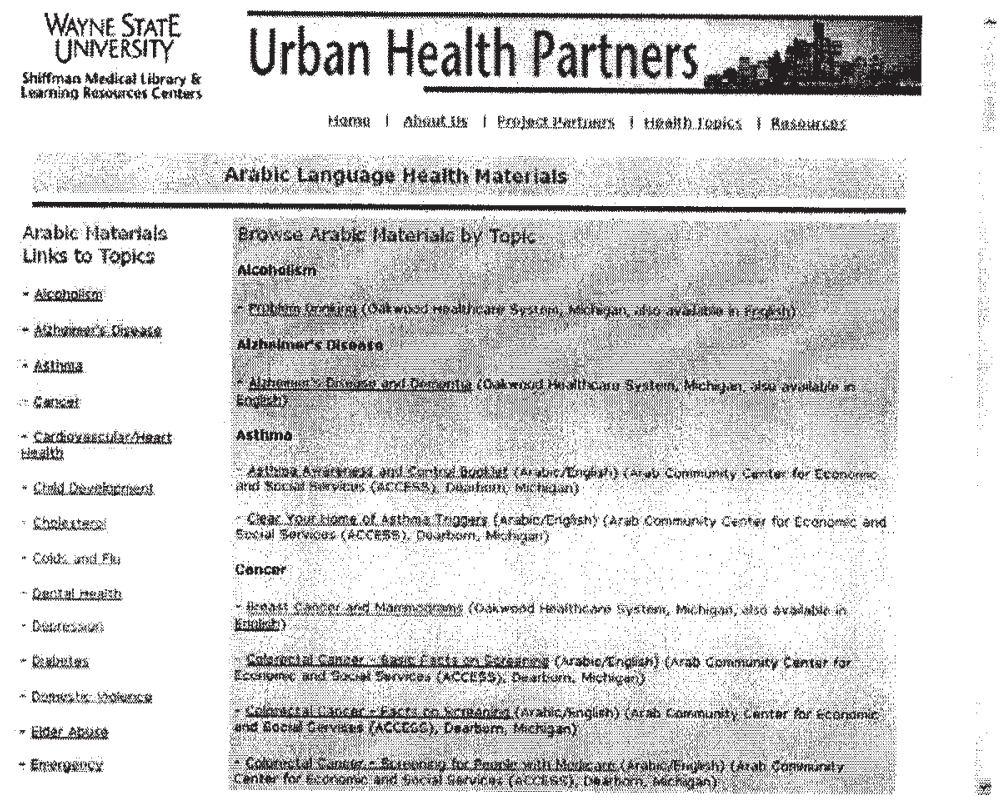

ness and Control," "Colorectal Cancer Screening Saves Lives," and "Diabetes Management and Reducing Risks" with culturally-relevant pictures and images developed by the Arab Community Center for Economic and Social Services. In addition, health information seekers can conveniently browse 17 different Arabic language publications from the Arab Community Center for Economic and Social Services, 22 handouts from local health care systems, and three brochures from a local health department. Whenever possible, links to English versions of the Arabic materials are provided. The majority of the Arabic language materials are available electronically in Portable Document Format (PDF). This format is helpful for displaying non-western characters and retaining the original formatting of health brochures, and is also printer-friendly. Additional organizations that have online materials in Arabic include the Michigan Department of Community Health, National Institute of Environmental Health Sciences, and the World Health Organization. The online collection of materials is supplemented with 
FIGURE 3. Arabic Language Materials Organized by Author/Organization

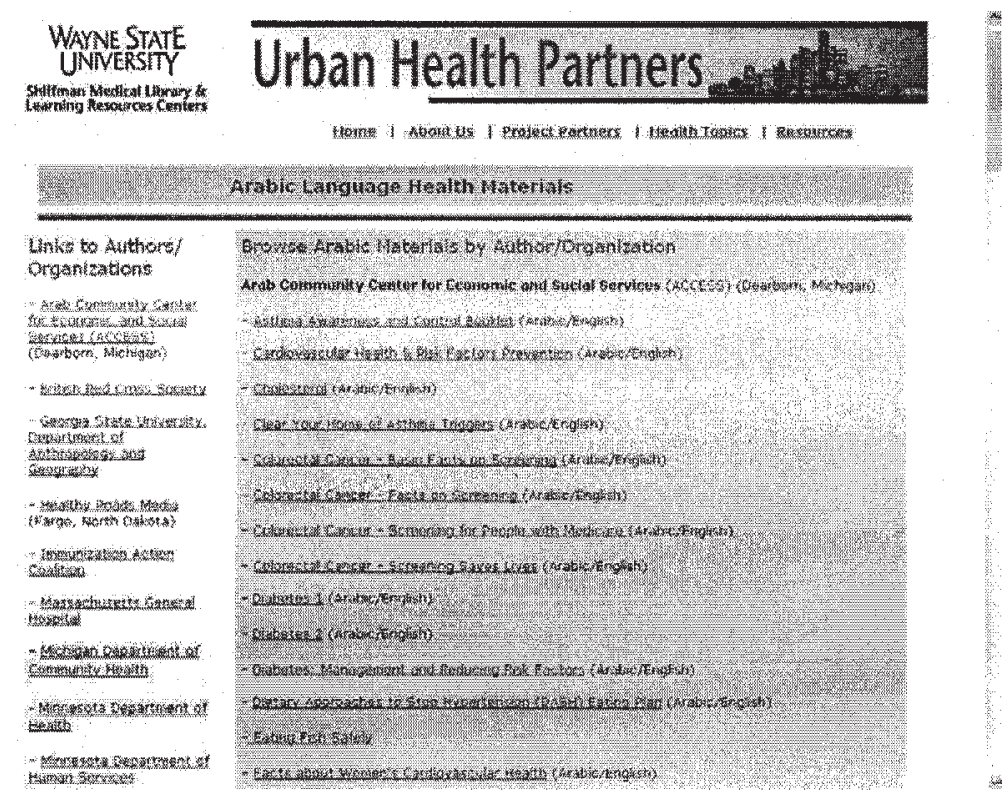

additional resources offering plain language and simple phrases in Arabic such as the American Hospital Association's "Point-to-Talk" booklet and a multilingual emergency phrasebook produced by the British Red Cross Society.

Librarians regularly update the online collection of Arabic language health materials and investigate new sources of health information for possible inclusion into the online collection. Links are checked regularly, and usage of the Web site is monitored. A review of "hits" to the Urban Health Partners Web site over the last eight months (3,019 hits between January 2005 and August 2005) shows that online users most frequently consulted the alphabetical list of Arabic language health materials (the "A-Z list"), followed by the list of materials organized by health topic, and then the list of materials organized by author or organization. Feedback from academic, hospital, and public librarians indicates a strong interest in the electronic Arabic health materials and the desire to see the online collection expand to better serve their clientele of diverse health information seekers. Reciprocal links with various li- 
braries were also established, including links with the 24 Languages project at the Spencer S. Eccles Health Sciences Library at the University of Utah <http://medstat.med.utah.edu/24languages $>$, HealthWeb $<$ http://www.healthweb.org>, Michigan Library Association's Multicultural Roundtable <http://www.mla.lib.mi.us/units/roundtable/mor>, and the National Network of Libraries of Medicine (NN/LM) Greater Midwest Region Web site $<\mathrm{http}: / \mathrm{nnlm}$.gov/gmr/mi $>$ to increase awareness of the availability of the electronic Arabic language health materials.

Project staff continues to present and promote the availability of the Arabic language health materials at community events, in particular events hosted by project partners. Staff will participate in the "4th National Conference on Health Issues in the Arab American Community" in 2006 and is expecting to reach an estimated 500 community members and community stakeholders. A significant element of this initiative is the importance of sustaining ongoing communication and providing regular updates to community organizations, English and Arabic media, and local elected officials regarding the progress of initiatives and emphasizing the importance and/or benefit to the community.

\section{FUTURE DIRECTIONS}

Libraries play a pivotal role in developing and distributing resources intended for diverse health information seekers. The Urban Health Partners program was successful in organizing and facilitating improved access to over 80 Arabic language health materials for Arab American consumers. Health providers, librarians, and other educators seeking quality health information in Arabic for their clientele will find this online collection of Arabic health materials to be a valuable resource. A wide variety of strategies are being used to encourage consumers to use the online collection of Arabic language health materials. These efforts include direct mail, specialty advertising, public service announcements, community and conference presentations, and publications in trade magazines and newsletters. Community partners working with Arab Americans also report that outreach efforts at mosques and schools are effective venues, and project staff is actively exploring opportunities to expand publicity and increase awareness of the availability of electronic health information in Arabic. It is anticipated that the distribution of various publicity materials, such as promotional pens and bookmarks, will heighten awareness of the availability of this collection of electronic Arabic language materials. Project staff is also 
working with a statewide library association to promote the availability of Arabic materials to public librarians and is actively seeking opportunities to partner with public libraries and other community partners to collaboratively expand the project's reach to neighboring communities.

Urban Health Partners staff will continue to build and enhance the online collection of Arabic materials and envision an Arab American Health Information Resource that can serve as an information portal providing comprehensive and current information about Arab American communities. Plans for enhancement of the Web site include the addition of resources for understanding Arabic culture, government resources, online publications, research reports, and other related links pertaining to the unique health disparities and health concerns of Arab Americans. Promising practices and models for community-based collaboration to effectively reach Arab American health consumers will also be included. The Urban Health Partners program at Wayne State University in Detroit serves as a model for community-based collaboration and initiatives aimed at addressing cultural, linguistic, and other barriers to reliable consumer health information.

Received: September 29, 2005

Revised: November 15, 2005

Accepted: November 17, 2005

\section{REFERENCES}

1. U.S. Census Bureau. "The Arab Population: 2000." 2003. Available: <http:// www.census.gov/prod/2003pubs/c2kbr-23.pdf>. Accessed: September 26, 2005.

2. Aswad, M. "Health Survey of the Arab, Muslim, and Chaldean American Communities in Michigan." 2001. Available: <http:/www.accesscommunity.org/documents/ AMCCAC.pdf>. Accessed: September 26, 2005.

3. Arab American Institute Foundation. "Demographics on Arab Americans." 2003. Available: <http://www.americanarab.com/main.cfm?location $=28>$. Accessed: September 26, 2005.

4. Hammad, A. "Effects of Behavioral Patterns, Lifestyle and Culture on Common Diseases in the Arab-American Community." 2002. Available: <https://www. accesscommunity. org//index.cfin?location $=13 \&$ subsectionid $=4 \&$ pageid $=1$ \& RecordID $=$ 45>. Accessed: September 26, 2005.

5. Workman, E.T.; Lomardo, N.T, and Le Ber, I.M. "Overcoming Language Barriers When Providing Health Information: Why We Should Care and What We Can Do." Joumal of Consumer Health on the Internet 7, no. 2 (2003): 23-32. 